\title{
Oxidative Stress and Molecular Reactions in Arteriogenic Erectile Dysfunction
}

\author{
Kazem M Azadzoi* and Mike Siroky \\ Department of Urology and Pathology, VA Boston Healthcare System and Boston University School of Medicine, Massachusetts, USA
}

\begin{abstract}
Vascular disorders are the leading causes of organic erectile dysfunction (ED). Most cases of arteriogenic ED are associated with vascular risk factors such as hypercholesterolemia, atherosclerosis, diabetes mellitus, hypertension, and smoking. These conditions impair vascular structure directly or indirectly by facilitating oxidative damage due to accumulation of reactive oxygen and nitrogen species such as superoxide $\left(\mathrm{O}_{2}{ }^{-}\right)$, hydrogen peroxide $\left(\mathrm{H}_{2} \mathrm{O}_{2}\right)$, hydroxyl radicals and peroxynitrite $\left(\mathrm{O}=\mathrm{NOO}{ }^{-}\right)$. Clinical studies have shown that the degree of arteriogenic ED cannot be predicted exclusively by the arterial integrity, suggesting that it involves local changes within penile smooth muscle cells, endothelium, nerves, and microvasculature. It is thought that arterial occlusion and subsequent lack of erectile tissue perfusion, nutrient deficiency, hypoxia, and accumulation of waste products constitute an environment hospitable to free radical formation and detrimental to nitric oxide (NO) bioavailability. Studies of animal and cell culture models have revealed that exposure to ischemia and hypoxia triggers a cascade of cellular and molecular changes in the erectile tissue with devastating impact on its structure and function. These alterations involve cytotoxic radicals, nitric oxide synthase (NOS), eicosanoids, neurotoxic elements, and growth factors and lead to impairment of NO/cGMP pathway, smooth muscle dysfunction, microvascular damage, and neurodegeneration. Ultimately, these events lead to erectile tissue fibrosis and the failure of penile veno-occlusive mechanism. These local changes in the hypoxic erectile tissue may explain the failure of revascularization surgery to completely cure arteriogenic ED and imply the need for newer therapeutic strategies to remove cytotoxic and neurotoxic elements from the chronically ischemic penis.
\end{abstract}

Key Words: Atherosclerosis, Ischemia, Oxidative stress, Erectile dysfunction

\section{Introduction}

Vascular disorders and persisting erectile tissue ischemia result in vasculogenic erectile dysfunction (ED) consisting of arteriogenic ED (cavernosal artery insufficiency) and veno-occlusive ED. ${ }^{1-3}$ Although frequently discussed separately, in reality these two mechanisms

Accepted for Publication: March 20, 2009

*Corresponding author: Kazem M. Azadzoi, Department of Urology and Pathology, VA Boston Healthcare System and Boston University School of Medicine, Phone: 617-232-9500 ext 5602, FAX: 857-364-4540, E-mail: kazadzoi@bu.edu often coexist in the same patient. Arterial endothelial injury and subsequent atherosclerotic disease are the leading causes of arteriogenic ED. ${ }^{2,3}$ Interestingly, cardiovascular disorders including coronary artery disease closely correlate with the incidence of $\mathrm{ED}$ in patients with vascular risk factors. ${ }^{4,5}$ Epidemiologic studies have shown that nearly $75 \%$ of men with coronary artery disease also suffer from ED. ${ }^{4,5}$ One explanation may be that vascular and cavernosal smooth muscle and endothelial cell dysfunction share the same risk factors. Therefore, arteriogenic ED may be an early signal of 
impending cardiovascular problems., ${ }^{4,5}$

The development of atherosclerotic lesion and occlusion of the hypogastric-pudendal arterial bed diminish arterial perfusion pressure, decrease arterial inflow to the lacunar spaces of the corpora cavernosa, and lead to progressive impairment of erectile tissue structure and function. ${ }^{6-12}$ This is evidenced by clinical and basic research data showing that decreased cavernosal perfusion pressure is the initial hemodynamic phenomenon that leads to a series of deleterious cytotoxic events with adverse impact on erectile tissue endothelium, smooth muscle, nerves and microvasculature. ${ }^{7,10-16}$ In this review, we summarize oxidative activities and molecular reactions in arteriogenic ED that result from prolonged exposure to ischemia.

\section{The Role of Hypoxia}

Oxygen tension in cavernosal blood has been reported to be decreased in patients with arteriogenic ED and it is quite likely that oxygen tension acts to regulate erectile tissue structure and function. ${ }^{17}$ Under hypoxic conditions, spontaneous contractile activity was eliminated in cavernosal muscle strips and basal tissue tension was reduced to a minimum. In this study, neither electrical field stimulation nor pharmacological agents could induce additional relaxation and alpha-adrenergic agonists produced little or no contraction. In an in vitro study of rabbit erectile tissue under hypoxic conditions $\left(\mathrm{pO}_{2}=10 \mathrm{~mm} \mathrm{Hg}\right)$, contractions elicited by norepinephrine, endothelin-1 or potassium were attenuated. $^{18}$ The hypoxia-induced relaxation was not affected by the removal of the endothelium.

Oxygen tension also regulates the ability of cavernosal smooth muscle to relax in response to various stimuli. When human and rabbit corpus cavernosum tissue strips were exposed to arterial-like $\mathrm{pO}_{2}$ levels in organ baths, they relaxed in response to the endothelium-dependent dilator acetylcholine and to electrical stimulation of the autonomic dilator nerves. ${ }^{19}$
These NO-mediated responses were progressively inhibited as a function of decreasing $\mathrm{pO}_{2}$ levels. The exogenous $\mathrm{NO}$-induced relaxation was not impaired in a low $\mathrm{pO}_{2}$ environment. These results indicate that $\mathrm{NO}$ production is impaired under conditions of low $\mathrm{pO}_{2}$, thus promoting vasoconstriction. ${ }^{19}$

In organ culture, basal production of prostanoids, whether relaxant or constrictive, was decreased under hypoxic conditions. ${ }^{20}$ Although this inhibition was reversible with physiologic $\mathrm{pO}_{2}$, the recovery was delayed, requiring at least 2 hours of exposure to $21 \%$ oxygen to reestablish prostanoid production. When $\mathrm{pO}_{2}$ was increased to $100 \mathrm{mmHg}$, a rapid increase in prostaglandin levels was observed. PGE2 levels were higher than $\mathrm{PGF}_{2 \alpha \mathrm{a}}$ which were higher than $\mathrm{PG}_{\mathrm{D} 2}$ levels. Thromboxane A2 was undetectable. These data suggest that the amount and type of prostanoids produced by cavernosal smooth muscle is exquisitely sensitive to cavernosal $\mathrm{O}_{2}$ tension in the penis. Oxygen tension may also play a role in regulating erectile tissue structure by promoting synthesis of transforming growth factor beta $\left(\mathrm{TGF}_{\beta}\right)$, a factor that promotes fibrosis. ${ }^{21}$

\section{Oxidative Stress in Penile Ischemia}

Oxidative stress occurs when penile oxidative burden exceeds its antioxidant capacity. The mechanism of oxidative injury involves free radical incursion and subsequent lipid peroxidation, protein oxidation, and DNA damage. $^{22-25}$ Oxygen free radicals in a NO-containing environment tend to combine to form peroxynitrite $\left(\mathrm{O}=\mathrm{NOO}^{-}\right)$, a highly cytotoxic product of superoxide $\left(\mathrm{O}_{2}{ }^{-}\right)$and $\mathrm{NO}$ radical reaction. ${ }^{22}$ This reaction results in decreased synthesis and bioavailability of endothelial and neuronal $\mathrm{NO}$ and upregulation of proinflammatory cytokines, growth factors and tissue-specific receptors. $^{22-25}$ In the healthy penis, reactive oxygen species (ROS) such as $\mathrm{O}_{2}{ }^{-}$are tightly regulated by physiologic homeostatic mechanisms; ROS that are formed are detoxified by biological antioxidants. In penile ischemia, 
ROS levels exceed the antioxidant capacity of erectile tissue. ROS accumulation can initiate a chain reaction of redox sensitive signaling events involving cytokines, kinases and transcription factors that regulate the expression of genes and proteins influencing vasoconstriction, modification of the extracellular matrix and inflammatory processes. ${ }^{22-25}$ It is known that aspects of the atherogenic process stimulate ROS production, including vascular endothelial injury, penetration and accumulation of plaque in the arterial wall, macrophage activation and release of cytokines and growth factors that stimulate ROS-producing enzymes. ${ }^{26-28}$ Such changes may contribute to ROS formation and erectile tissue injury in arteriogenic ED. In addition, arterial insufficiency may limit antioxidant availability and alteration of mitochondrial function may generate excessive ROS in the ischemic penis.

\section{Molecular Reactions in Penile Ischemia}

Penile ischemia in arteriogenic ED triggers a cascade of molecular reactions involving hypoxia inducible factor (HIF), NOS subtypes, vascular endothelial growth factor (VEGF), nerve growth factor (NGF), and transforming growth factor beta (TGF-beta). ${ }^{12,29,30}$ HIF upregulation may be a primary reaction to ischemia that appears to regulate other hypoxia sensitive genes in the penis. These molecular reactions lead to profound changes in erectile tissue structure and function and may play a central
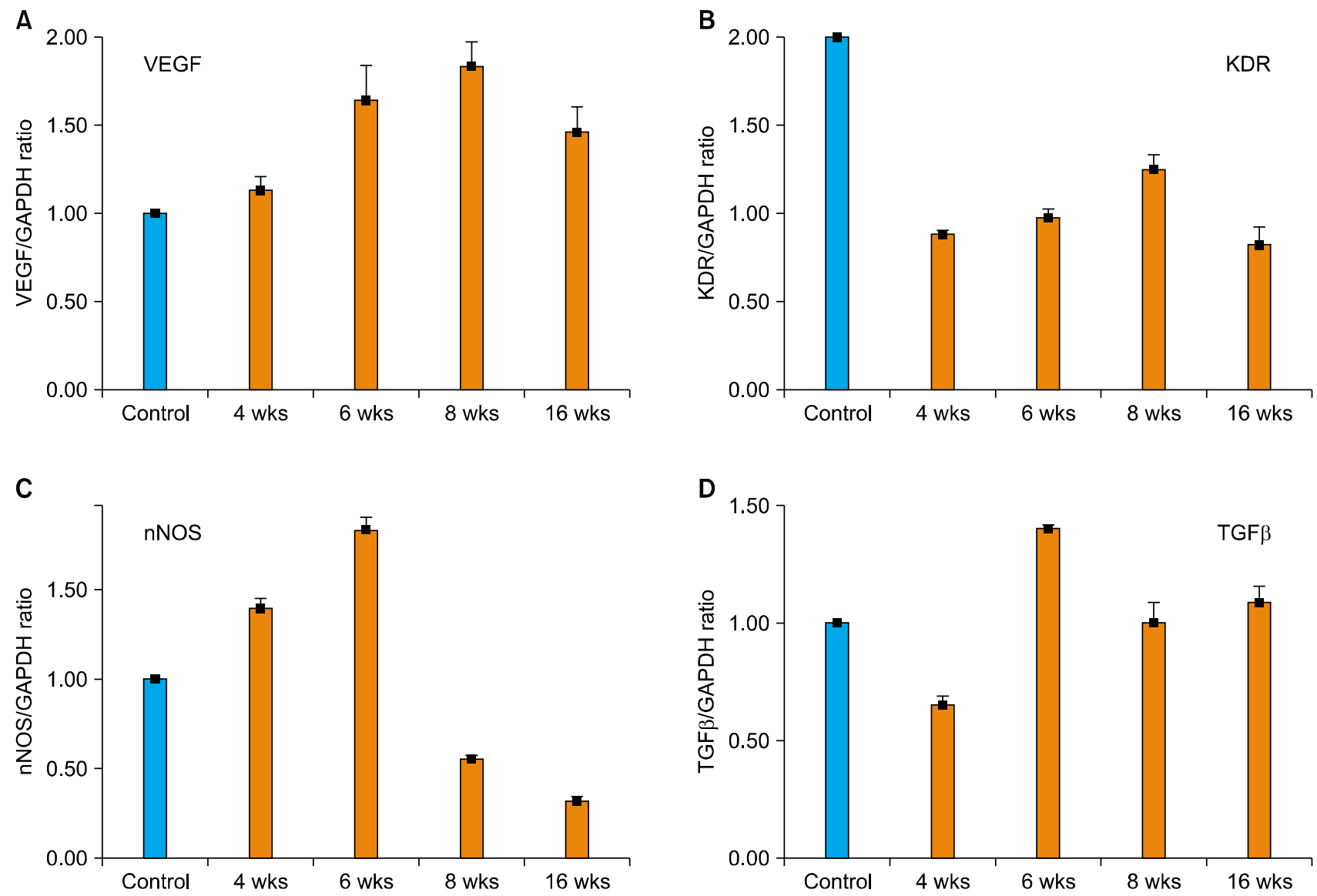

Fig. 1. This figure shows the effects of ischemia on cavernosal VEGF, VEGF receptor (KDR), nNOS, and TGF- $\beta$ gene expression. The ratio of the specific gene product and GAPDH is shown at each time point after the induction of cavernosal ischemia in the rabbit. VEGF levels show approximately a 2-fold increase compared with normal at 8 weeks of ischemia, with a reduction at 16 weeks. KDR levels decrease initially to half of normal and then gradually increase up to 8 weeks of ischemia. nNOS levels show a 2-fold increase at 6 weeks of ischemia and it decreases thereafter. TGF $\beta$ levels increase at 8 weeks of ischemia, but return to normal levels by 16 weeks. (From Wang et al, Int J Impot Res 16: 403-411, 2004). 
role to the pathophysiology of arteriogenic ED.

\section{Changes in NOS expression}

Semi-quantitative RT-PCR of rabbit erectile tissue has shown that neuronal NOS (nNOS) gene expression initially increases in response to ischemia (Fig. 1). ${ }^{29}$ The nNOS levels then gradually decrease significantly in a time-dependent manner over the course of ischemia (Fig. 1). ${ }^{29}$ The initial upregulation of nNOS in the ischemic erectile tissue may be a physiologic defense mechanism to maintain NO levels; however, it seems to fail after long-term exposure to ischemia.

Western blotting analysis of ischemic rabbit cavernosal tissues has shown that nNOS protein levels remain unchanged in the early stages of ischemia, suggesting that under the ischemic conditions increased nNOS transcript levels may not be capable of stimulating nNOS protein synthesis. ${ }^{12,29}$ One possible explanation may be that at the early stages of ischemia, although nNOS gene expression is upregulated, the environment ensuring for stimulating nNOS protein expression may not be available. Western blotting has shown that both nNOS and eNOS proteins dramatically decrease after prolonged cavernosal ischemia in the rabbit. ${ }^{12}$ In the later stages of ischemia, decreased transcript levels was found to correlate with reduced nNOS protein levels. ${ }^{12,29}$

Immunohistochemical staining of rabbit erectile tissue has shown that the localization and abundance of nNOS, eNOS and inducible NOS (iNOS) in corpus cavernosum dramatically change with ischemia. ${ }^{12}$ Whereas nNOS and eNOS expressions decrease over the course of cavernosal ischemia, iNOS expression increases. ${ }^{12}$ Based on these findings, it appears that while constitutive NOS (cNOS) is more abundant in healthy erectile tissue, iNOS dominates the erectile tissue under ischemic/hypoxic conditions. Such a disproportionate change in NOS isoforms may be of great importance in the pathophysiology of vasculogenic ED. The precise mechanism by which ischemia inhibits the constitutive NOS while upregulating the inducible form is not known. It is speculated that such a disproportionate change in iNOS versus
nNOS and eNOS expression may play a role in diabetic ED. Aging-related ED is also accompanied by increased iNOS expression in rat erectile tissue. This is believed to play a role in collagen accumulation and apoptosis of erectile tissue. Studies with a rat model of Peyronie's disease have shown that upregulation of iNOS is accompanied by downregulation of cNOS and erectile dysfunction. Inhibition of iNOS in this model was found to reduce $\mathrm{ED}$.

\section{Changes in VEGF expression}

The development and growth of the vascular system, referred to as angiogenesis and vasculogenesis, are regulated by angiogenic growth factors. VEGF is a potent angiongenic growth factor that was initially purified from tumor cell lines as a specific mitogen for endothelial cells in vitro.

Studies with the rabbit model have shown that ischemia alters the expression of both VEGF and its receptors in erectile tissue. ${ }^{29}$ Immunohistochemical analysis with antiVEGF antibodies have shown that positively stained areas within the corpus cavernosum are greater in the early stages of cavernosal ischemia in comparison to age-matched controls. ${ }^{29}$ After long- term ischemia, however, the VEGF-positive stained areas within the corpus cavernosum were found to dramatically diminish. The number of ischemic endothelial cells that stained positively for VEGF was similar to the controls. ${ }^{29}$

Semi-quantitative RT-PCR analyses of rabbit erectile tissue have shown that VEGF gene expression initially increases in response to ischemia and then it gradually decreases over the course of ischemia reaching to a level significantly lower than the levels of the early stages of ischemia (Fig. 1). ${ }^{29}$ This study has shown that the VEGF receptors may be more sensitive to ischemia than VEGF. The levels of the VEGF receptor KDR dramatically reduces to approximately $40 \%$ of the control levels in the early stages of ischemia (Fig. 1). ${ }^{29}$ Although KDR levels in the ischemic tissues tends to increase over the course of ischemia, they only reach $60 \%$ of the control levels. Accordingly, it was found 
that KDR levels decrease significantly to approximately $40 \%$ of the control group after prolonged ischemia along with the reduction in VEGF levels (Fig. 1). ${ }^{29}$ These observations suggest that VEGF may be secreted in order to preserve the erectile tissue vascular function in response to ischemia. ${ }^{30,31}$ Prolonged ischemia, however, appears to overcome this reaction.

\section{Changes in TGF-beta expression}

In a variety of organ systems and diseases, TGF- $\beta$ has been implicated in fibrosis. ${ }^{32}$ Ischemia and hypoxia have been shown to induce TGF- $\beta 1$ protein in blood vessels, and TGF- $\beta 1$ mRNA in human corpus cavernosum smooth muscle cells. ${ }^{33}$ Regardless of the initial source, TGF- $\beta$ has been shown to autoinduce its own mRNA and increase either the synthesis or availability of its receptors in human corpus cavernosum smooth muscle cells. ${ }^{34}$ It is suggested that once the process begins, ischemia-induced fibrosis could proceed unabated. ${ }^{32-34}$

Clinical studies have shown that cavernosal TGFbeta1 expression is significantly greater in vasculogenic ED patients than in the control subjects or psychogenic ED patients. ${ }^{35}$ TGF-betal type II receptor expression was also found to be significantly greater in vasculogenic ED compared with control subjects and patients

\section{A}

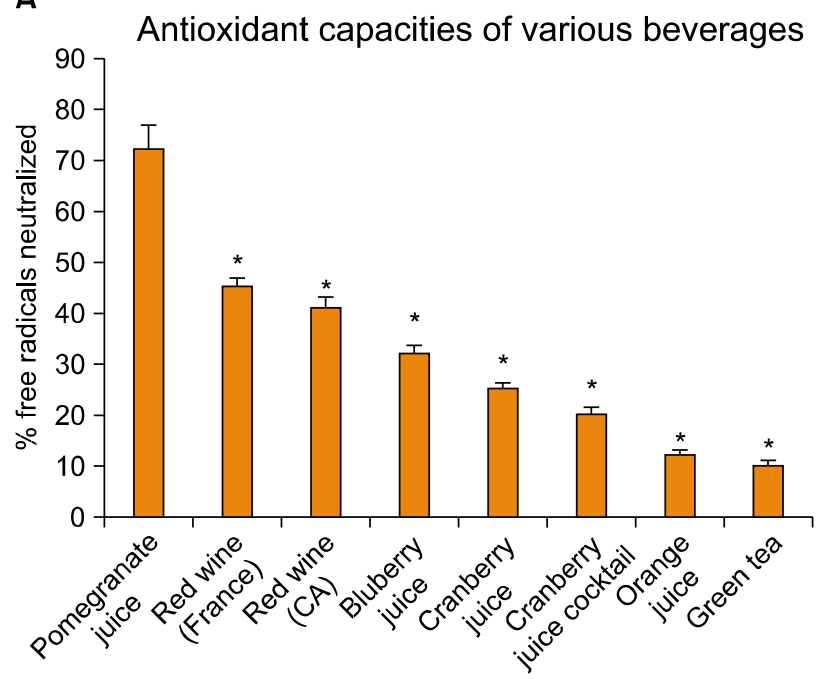

with psychogenic and neurogenic ED. ${ }^{35}$ Patients with vascular risk factors such as hyperlipidemia and atherosclerosis were found to have significantly greater degrees of cavernosal fibrosis than those without these conditions. ${ }^{35}$ Furthermore, this study has shown that the abundance of collagen fibers closely correlates with both TGF-beta1 and TGF-beta1 receptor II expression, suggesting a role of TGF-beta1 and its receptor II in cavernosal fibrosis in vasculogenic ED patients. ${ }^{35}$

Exogenous treatment with TGF-beta has been shown to induce a 2.5- to 4.5-fold increase in the synthesis of types I and III collagen. ${ }^{36}$ This effect was reduced by adding the eicosanoid PGE $1 .^{34}$ In a rabbit model utilizing intracavernosal injection of TGF-beta, histomorphometry showed dose-dependent decreases in the percentage of corporal smooth muscle with TGF-beta treatment. ${ }^{36}$

\section{Potential Role of Antioxidants in Arteriogenic ED}

Antioxidants such as vitamin $\mathrm{E}$ and vitamin $\mathrm{C}$ have been used widely in clinical practice to protect the body from harmful free radicals. ${ }^{26-28}$ Other families of antioxidants with a more potent free radical scavenging

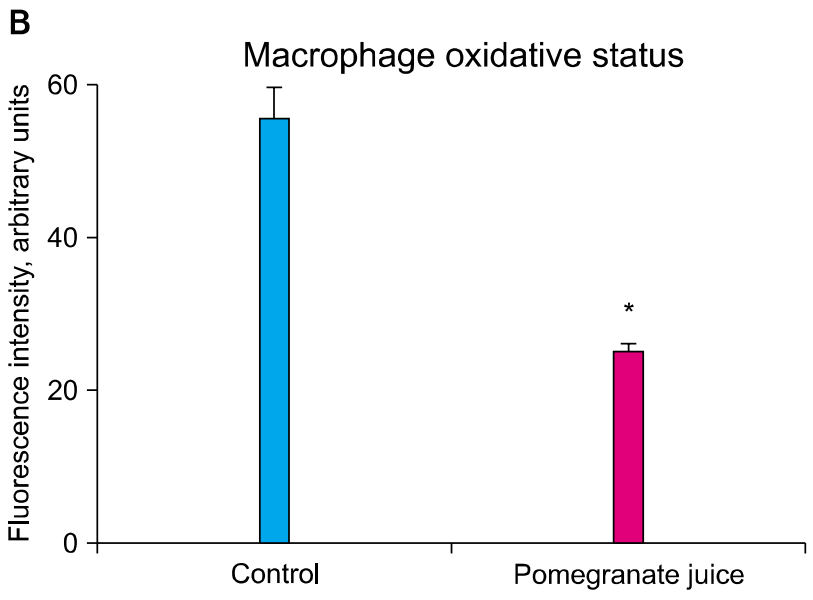

Fig. 2. The left panel shows percentage of free radicals neutralized by several beverages known for their antioxidant capacity. The right panel shows antioxidant effect of pomegranate juice on macrophage (J-774. A1 cell line) oxidative status. Inhibition of cellular oxidative stress was measured by the DCFH fluorescence assay using the FACS system (From Azadzoi et al, J Urology 174: 386-93, 2005). 
capacities, such as polyphenols, might also be effective in protecting the cardiovascular system. Indeed, consumption of red wine or pomegranate juice polyphenols by mice as well as by humans was shown to prevent oxidative stress and delay the development of atherogenesis and atherosclerotic lesion. ${ }^{26-28}$ Studies of the effects of dietary antioxidants in an experimental model of ED promises clinical implication. ${ }^{37}$ In this study, the antioxidant activity of known antioxidant beverages such as pomegranate juice, red wine, blueberry juice, cranberry juice, orange juice, and green tea was examined by spectrophotometry. ${ }^{37}$ Pomegranate juice demonstrated the highest free radical scavenging capacity (Fig. 2). After this, the effects of long-term pomegranate juice intake on intracavernosal blood flow and penile erection was examined in the rabbit model of arteriogenic ED. The data revealed loss of erectile tissue relaxation, reduced eNOS and nNOS and increased iNOS expression, and diffused erectile tissue fibrosis in the arteriogenic ED model. These changes were associated with increased cavernosal levels of the oxidatively modified product isoprostane 8 -epi-PGF2 $\alpha$, suggesting oxidative stress in the ED model. Long-term intake of pomegranate juice increased intracavernosal blood flow and improved erectile response and smooth muscle relaxation in both ED and control groups of animals (Fig. 3). Furthermore, antioxidant therapy reduced erectile tissue fibrosis in the ED group. ${ }^{37}$ These observations suggest that antioxidants may neutralize superoxides and allow $\mathrm{NO}$ to linger long enough to exert its biological effects in the penis.

In addition to effects on $\mathrm{NO}$, antioxidants may also act via angiotensin II, a key intermediary in vasoconstriction. Angiotensin II is formed from angiotensin I via angiotensin converting enzyme (A-C-E).$^{38-40}$ This process is regulated by ROS, and blocked by the addition of antioxidants. Pomegranate polyphenols have been shown to significantly inhibit A-C-E in humans. The antifibrosis effect of pomegranate in the ED model is consistent with the reported efficacy of antioxidants in attenuating the tubulointerstitial disease in rats with nephrosis. Oxidative stress and the formation of oxidative products in arteriogenic ED are presumed to play significant roles in erectile tissue fibrosis. Oxidative products

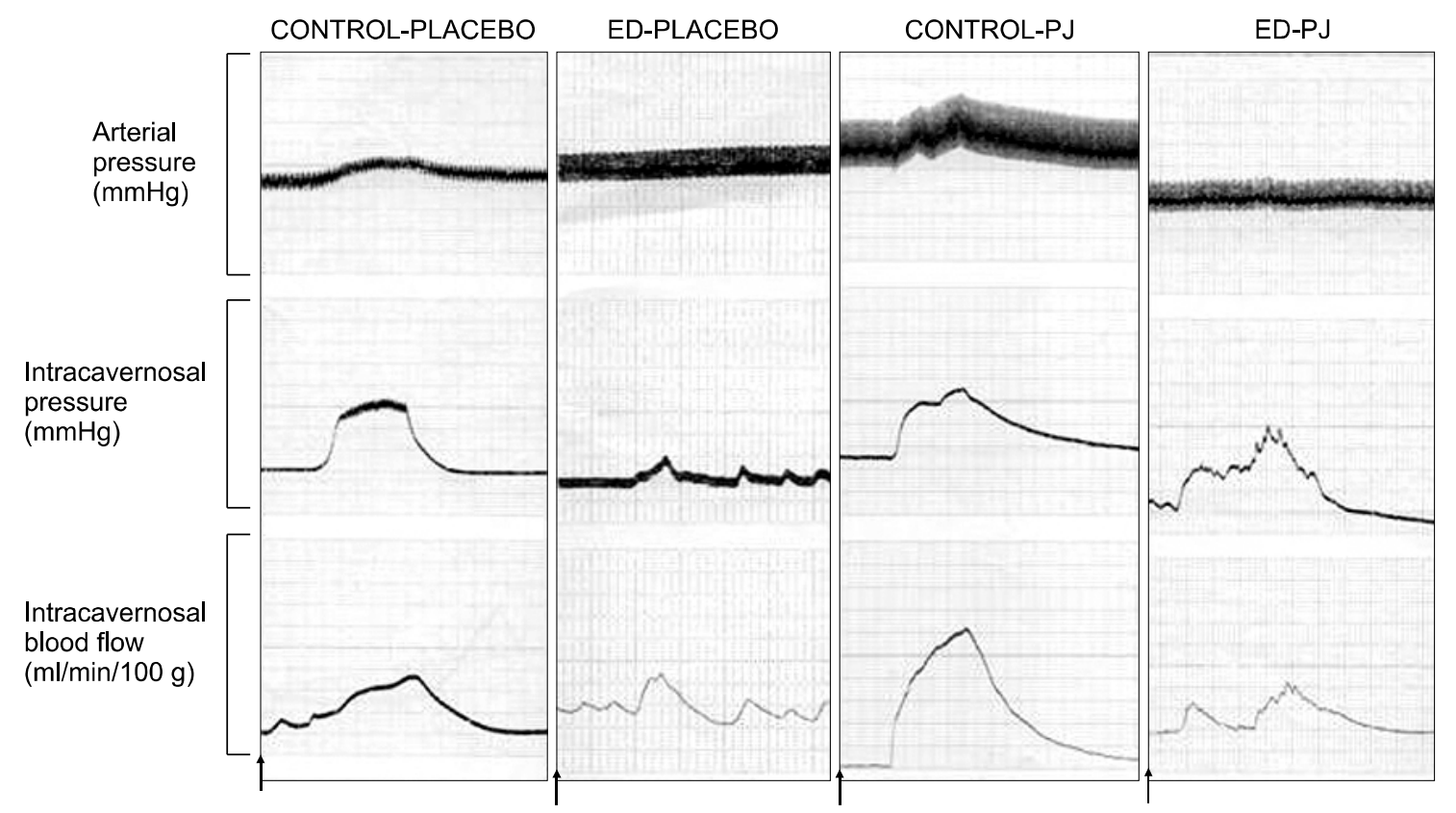

Fig. 3. This figure shows effects of the antioxidant beverage pomegranate juice (PJ) on erectile response to cavernosal nerve stimulation in the rabbit model. Long-term antioxidant consumption improved intracavernosal blood flow and erectile response in both arteriogenic ED and age-matched control animals. Arrows point to the start of electrical nerve stimulation (From Azadzoi et al, J Urology 174: 386-93, 2005). 
are known to stimulate TGF-beta 1 production and upregulate the gene expression of fibronectin. It is thought that the newly-produced TGF-beta 1 in response to oxidative stress stimulates fibronectin expression. ${ }^{38-40}$ It has been shown that collagen degradation is affected by ROS. In atherosclerotic rabbits, metalloproteinases secreted from macrophage foam cells degrade the cellular matrix. N-acetylcysteine, an antioxidant, prevents this metalloproteinase release. These observations suggest that antioxidant therapy may be a promising option in preventing or reversing erectile tissue fibrosis.

The pathophysiology of arteriogenic ED is more complicated than previously thought, involving intricate molecular reactions and fundamental changes in erectile tissue structure and function mediated by hypoxia and oxidative stress. Oxidative radicals in the ischemic penis may play a central role in erectile smooth muscle dysfunction, loss of endothelial cells, neural injury, and fibrosis. These local changes in the ischemic erectile tissue may explain why revascularization and, in some cases, venous leak surgery fail to completely cure vasculogenic ED. These observations suggest that hemodynamic examination alone can-not precisely predict the degree of vasculogenic erectile dysfunction. Successful pharmacological and surgical management of vasculogenic ED may depend on identifying patients in their early stage prior to the structural and functional changes of erectile tissue. Further insight into the cellular and molecular mechanism of vasculogenic ED may lead to newer prophylactic and therapeutic strategies to prevent, delay or reverse this problem. Therapeutic strategies to protect penile smooth muscle, endothelium, and nerves from free radical injury may enhance the efficacy of surgical and pharmacologic interventions in arteriogenic ED.

\section{References}

1. Krane RJ, Goldstein I, Saenz de Tejada I. Impotence. $N$ Engl J Med 1989;32:1648-59.

2. Grein U, Schubert GE. Arteriosclerosis of penile arteries: histological findings and their significance in the treatment of erectile dysfunction.
Urol Int 2002;68:261-4.

3. Siroky MB, Azadzoi KM. Vasculogenic Erectile Dysfunction: Newer Therapeutic Strategies. J Urol 2003;170:24-30.

4. Solomon H, Man JW, Jackson G. Erectile dysfunction and the cardiovascular patient: endothelial dysfunction is the common denominator. Heart 203;89:251-3.

5. Kloner RA, Mullin SH, Shook T, Matthews R, Mayeda G, Burstein $\mathrm{S}$, et al. Erectile Dysfunction in the Cardiac Patient: How common and should we treat it? J Urol 2003;170:46-50.

6. Levine FJ, Greenfield AJ, Goldstein I. Arteriographically-determined occlusive disease within the hypogastric-cavernous bed in impotent patients following blunt perineal and pelvic trauma. J Urol 1990;144: 1147-53.

7. Azadzoi KM, Park K, Andry C, Goldstein I, Siroky MB. Relationship between cavernosal ischemia and corporal veno-occlusive dysfunction in an animal model. $J$ Urol 1997;157:1011-7.

8. Aboseif SR, Breza J, Orvis BR, Lue TF, Tanagho EA. Erectile response to acute and chronic occlusion of the internal pudendal and penile arteries. J Urol 1989;141:398-402.

9. Munarriz RM, Yan QR, Nehra A, Udelson D, Goldstein I. Blunt trauma: the pathophysiology of hemodynamic injury leading to erectile dysfunction. $J$ Urol 1995;153:1831-40.

10. Azadzoi KM, Goldstein I, Siroky MB, Traish AM, Krane RJ, Saenz de Tejada I. Mechanisms of ischemia-induced cavernosal smooth muscle relaxation impairment in a rabbit model of vasculogenic erectile dysfunction. J Urol 1998;160:2216-22.

11. Azadzoi KM, Krane RJ, Saenz de Tejada I, Goldstein I, Siroky MB. Relative roles of cyclooxygenase and nitric oxide synthase pathways in ischemia-induced increased contraction of cavernosal smooth muscle. $J$ Urol 1999;161:1324-8.

12. Azadzoi KM, Master TA, Siroky MB. Effect of chronic ischemia on constitutive and inducible nitric oxide synthase expression in erectile tissue. $J$ Androl 2004;25:382-8.

13. Wespes E, Sattar AA, Golzarian J, Wery D, Daoud N, Schulman CC. Corporeal veno-occlusive dysfunction: predominantly intracavernous muscular pathology. $J$ Urol 1997;157:1678-80.

14. Nehra A, Goldstein I, Pabby A, Nugent M, Huang YH, de las Morenas A, et al. Mechanisms of venous leakage: a prospective clinicopathological correlation of corporeal function and structure. $J$ Urol 1996;156:1320-9.

15. Sattar AA, Salpigides G, Vanderhaeghen JJ, Schulman CC, Wespes E. Cavernous oxygen tension and smooth muscle fibers: relations and function. $J$ Urol 1995;154:1736-9.

16. Persson C, Diederichs W, Lue TF, Yen TS, Fishman IJ, McLin PH. Correlation of altered penile ultrastructure with clinical arterial evaluation. J Urol 1989;142:1462-8.

17. Tarhan F, Kuyumcuoglu U, Kolsuz A, Ozgul A, Canguven O. Cavernous oxygen tension in the patients with erectile dysfunction. Int $J$ Impot Res 1997;9:149-53.

18. Kim NN, Kim JJ, Hypolite J, Garcia-Diaz JF, Broderick GA, Tornheim $\mathrm{K}$, et al. Altered contractility of rabbit penile corpus cavernosum smooth muscle by hypoxia. J Urol 1996;155:772-8.

19. Kim N, Vardi Y, Padma-Nathan H, Daley J, Goldstein I, Saenz de Tejada I. Oxygen tension regulates the nitric oxide pathway. Physiological role in penile erection. J Clin Invest 1993;91:437-42.

20. Daley JT, Brown ML, Watkins T, Traish AM, Huang YH, Moreland $\mathrm{RB}$, et al. Prostanoid production in rabbit corpus cavernosum: I. 
regulation by oxygen tension. $J$ Urol 1996;155:1482-7.

21. Moreland RB. Is there a role of hypoxemia in penile fibrosis: a viewpoint presented to the Society for the Study of Impotence. Int $J$ Impot Res 1998;10:113-20.

22. Darley-Usmar V. White R. Disruption of vascular signaling by the reaction of nitric oxide with superoxide: implication for cardiovascular disease. Exp Physiol 1997;82:305-16.

23. Xie Z, Wei M, Morgan TE, Fabrizio P, Han D, Finch CE, et al. Peroxynitrite mediates neurotoxicity of amyloid beta-peptide 1-42 and lipopolysaccharide-activated microglia. J Neurosci 2002;22:3484-92.

24. Belló-Klein A, Bock PM, Travacio M, Senna SM, Llesuy S, de Bittencourt PI Jr, et al. Myocardial oxidative stress and antioxidants in hypertension as a result of nitric oxide synthase inhibition. Cardiovasc Toxicol 2001;1:43-50.

25. Qutub AA, Popel AS. Reactive oxygen species regulate hypoxiainducible factor 1alpha differentially in cancer and ischemia. Mol Cell Biol 2008;28:5106-19.

26. Kinlay S, Behrendt D, Fang JC, Delagrange D, Morrow J, Witztum $\mathrm{JL}$, et al. Long-term effect of combined vitamins $\mathrm{E}$ and $\mathrm{C}$ on coronary and peripheral endothelial function. $J$ Am Coll Cardiol 2004;43:629-34.

27. Fuhrman B, Lavy A, Aviram M. Consumption of red wine with meals reduces the susceptibility of human plasma and low-density lipoprotein to lipid peroxidation. Am J Clin Nutr 1995;61:549-54.

28. Hayek T, Fuhrman B, Vaya J, Rosenblat M, Belinky P, Coleman R, et al. Reduced progression of atherosclerosis in apolipoprotein E-deficient mice following consumption of red wine, or its polyphenols quercetin or catechin, is associated with reduced susceptibility of LDL to oxidation and aggregation. Arterioscler Thromb Vasc Biol 1997;17:2744-52.

29. Wang T, Soker S, Atala A, Siroky MB, Azadzoi KM. Alterations in angiogenic growth factors and neuronal nitric oxide synthase expression in chronic cavernosal ischemia. Int J Impot Res 2004;16:403-11.

30. Lin CS, Ho HC, Chen KC, Lin G, Nunes L, Lue TF. Intracavernosal injection of vascular endothelial growth factor induces nitric oxide synthase isoforms. BJU Int 2002;89:955-60.
31. Byrne RR, Henry GD, Rao DS, Huynh TT, Pippen AM, Annex BH, et al. Vascular endothelial growth factor restores corporeal smooth muscle function in vitro. J Urol 2001;165:1310-5.

32. Border WA, Noble NA. Transforming growth factor beta in tissue fibrosis. New Engl J Med 1994;331:1286-92.

33. Moreland RB, Huang YH, Munnariz R, Nehra A, Goldstein I, Saenz de Tejada I. Oxygen tension regulates the expression of transforming growth factor b1 in human corpus cavernosum smooth muscle. $J$ Urol 1995;153:509.

34. Moreland RB, Traish AM, McMillin MA, Smith B, Goldstein I, Saenz de Tejada I. PGE1 suppresses the induction of collagen synthesis by transforming growth factor-b1 in human corpus cavernosum smooth muscle. J Urol 1995;153:826-34.

35. Ryu JK, Han JY, Chu YC, Song SU, Lee KH, Yoon SM, et al. Expression of cavernous transforming growth factor-betal and its type II receptor in patients with erectile dysfunction. International $J$ Androl 2004;27:42-9.

36. Nehra A, Gettman MT, Nugent M, Bostwick DG, Barrett DM, Goldstein I, et al. Transforming growth factor-betal (TGF-betal) is sufficient to induce fibrosis of rabbit corpus cavernosum in vivo. $J$ Urol 1999;162:910-5.

37. Azadzoi KM, Schulman RN, Aviram M, Siroky MB. Oxidative stress in arteriogenic erectile dysfunction: prophylactic role of antioxidants. $J$ Urol 2005;174:386-93.

38. Chade AR, Krier JD, Rodriquez-Porcel M, Breen JF, McKusick MA, Lerman A, et al. Comparison of acute and chronic antioxidant interventions in experimental renovascular disease. Am J Physiol Renal Physiol 2004;286:1079-86.

39. Mangoush O, Nakamura K, Al-Ruzzeh S, Athanasiou T, Chester A, Amrani M. Effect of ascorbic acid on endothelium-dependent vasodilatation of human arterial conduits for coronary artery bypass grafting. Eur J Cardiothorac Surg 2003;24;541-6.

40. Fitzpatrick DF, Bing B, Rohdewald P. Endothelium-dependent vascular effects of Pycnogenol. J Cardiovasc Pharmacol 1998;32;509-15. 